\title{
DESENVOLVIMENTO E CARACTERIZAÇÃO DE NANOEMULSÕES POLIMÉRICAS PREPARADAS A PARTIR DE ÓLEOS DE UVA, ALGODÃO E AZEITE
}

\author{
M. M. B. PELISSARI ${ }^{1}$, A. V. de PAULA ${ }^{1}$, F. L. PRIMO ${ }^{1 *}$ \\ ${ }^{1}$ Universidade Estadual Paulista, UNESP, Departamento de Bioprocessos e Biotecnologia \\ e-mail para contato:*flprimo@fcfar.unesp.br
}

\begin{abstract}
RESUMO - Nanoemulsões (NE) são sistemas coloidais com tamanho de partículas submicrônico. Esses sistemas são obtidos pelo método de adição direta de fases, em que uma fase orgânica contendo óleo, solvente e um polímero é gotejada em uma fase aquosa contendo água ultrapura e um tensoativo sob agitação constante e temperatura controlada. O processo de emulsificação final é obtido à pressão reduzida em rota-evaporação para extração do solvente orgânico. Neste trabalho, utilizaram-se três diferentes tipos de óleos vegetais do tipo azeite, uva e algodão em diferentes frações de volumes em sua composição. Após o preparo das NE, análises de tamanho e potencial Zeta $(\zeta)$ foram realizadas para avaliar as características fundamentais de cada formulação, bem como determinar a estabilidade físico-química desses nanomateriais em função do tempo de armazenamento.
\end{abstract}

\section{INTRODUÇÃO}

Nanoemulsões (NE) são definidas como sistemas coloidais formados por dois líquidos imiscíveis, geralmente óleo e água, em que um dos líquidos apresenta-se disperso no outro, na presença de tensoativos. Assim como as emulsões comuns, as NE não são consideradas sistemas coloidais termodinamicamente estáveis, porém, ao analisarmos a cinética de desestabilização de tais coloides, vê-se que o tempo necessário para total desestabilização do sistema é lento, sendo alcançado depois de vários meses, ocasionado pelo tamanho muito pequeno que suas gotículas possuem. Com isso, pode-se considerar que as NE são sistemas coloidais estáveis, com potencial para diversas aplicações, destacando-se o emprego na indústria farmacêutica, cosmecêutica e alimentícia (Anton; Vandamme, 2011).

\section{MATERIAS E MÉTODOS}

Um planejamento experimental foi realizado, em que foi definido o desenvolvimento de NE com diferentes tipos e volumes dos óleos, conforme mostrado na Tabela 1. 
Tabela 1 - Desenho experimental com frações de diferentes óleos utilizados para o desenvolvimento de cada nanoemulsão

\begin{tabular}{ccc}
\hline Óleo de Uva $(\mu \mathrm{L})$ & Óleo de Algodão $(\mu \mathrm{L})$ & Azeite $(\mu \mathrm{L})$ \\
\hline $125 / 10000$ & $125 / 10000$ & $125 / 10000$ \\
$250 / 10000$ & $250 / 10000$ & $250 / 10000$ \\
$350 / 10000$ & $350 / 10000$ & $350 / 10000$ \\
\hline
\end{tabular}

O nanomaterial polimérico foi preparado utilizando-se o método de adição direta de fases, conforme mostrado na Figura 1. O processo iniciou-se em duas fases, a aquosa, em que foi usada água ultra-pura do tipo Milli- $Q$ e um tensoativo iônico Kolliphor 188 (Sigma Aldrich), e a fase orgânica (acetona p.a.) onde foi dissolvido, a $55{ }^{\circ} \mathrm{C}$, o Lipoid S100 (Lipoid AG), um glicocero-fosfolipídeo, juntamente com a fase oleosa, seguindo-se o planejamento apresentado na Tabela 1. Após o preparo de ambas as fases, estas foram misturadas em um reator de $200 \mathrm{~mL}$, sob agitação e aquecimento constante $\left(55^{\circ} \mathrm{C}\right)$ para início da emulsificação. Após esse processo, as formulações foram levadas ao rota-evaporador (modelo R300, da Buchi, Alemanha), para separação da acetona e finalização do processo de emulsificação. As análises foram feitas para determinar o diâmetro médio dos coloides nesse sistema, assim como seu potencial Zeta $(\zeta)$ e o índice de Polidispersividade (PdI), empregando-se a técnica de espalhamento dinâmico de luz (Dynamic Light Scattering - DLS), utilizando um equipamento Zetasizer, modelo ZS90 da Malvern Instruments.

Figura 1 - Representação do método de adição direta de fases para obtenção do processo de nanoemulsificação

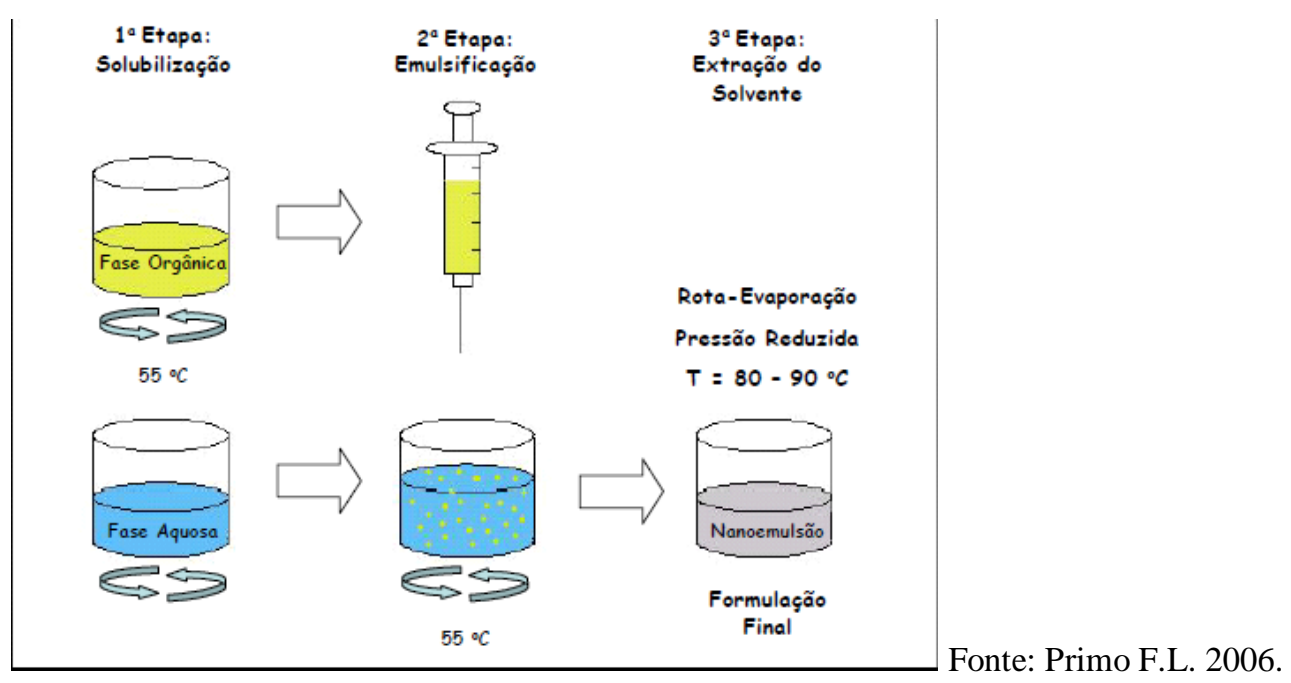


Após o processo de nanoemulsificação, as formulações apresentam-se translúcidas, conforme mostrado na Figura 2:

Figura 2 - formulações após o processo de nanoemulsificação

a) NE com óleo de algodão

b) NE com óleo de uva

c) NE com azeite

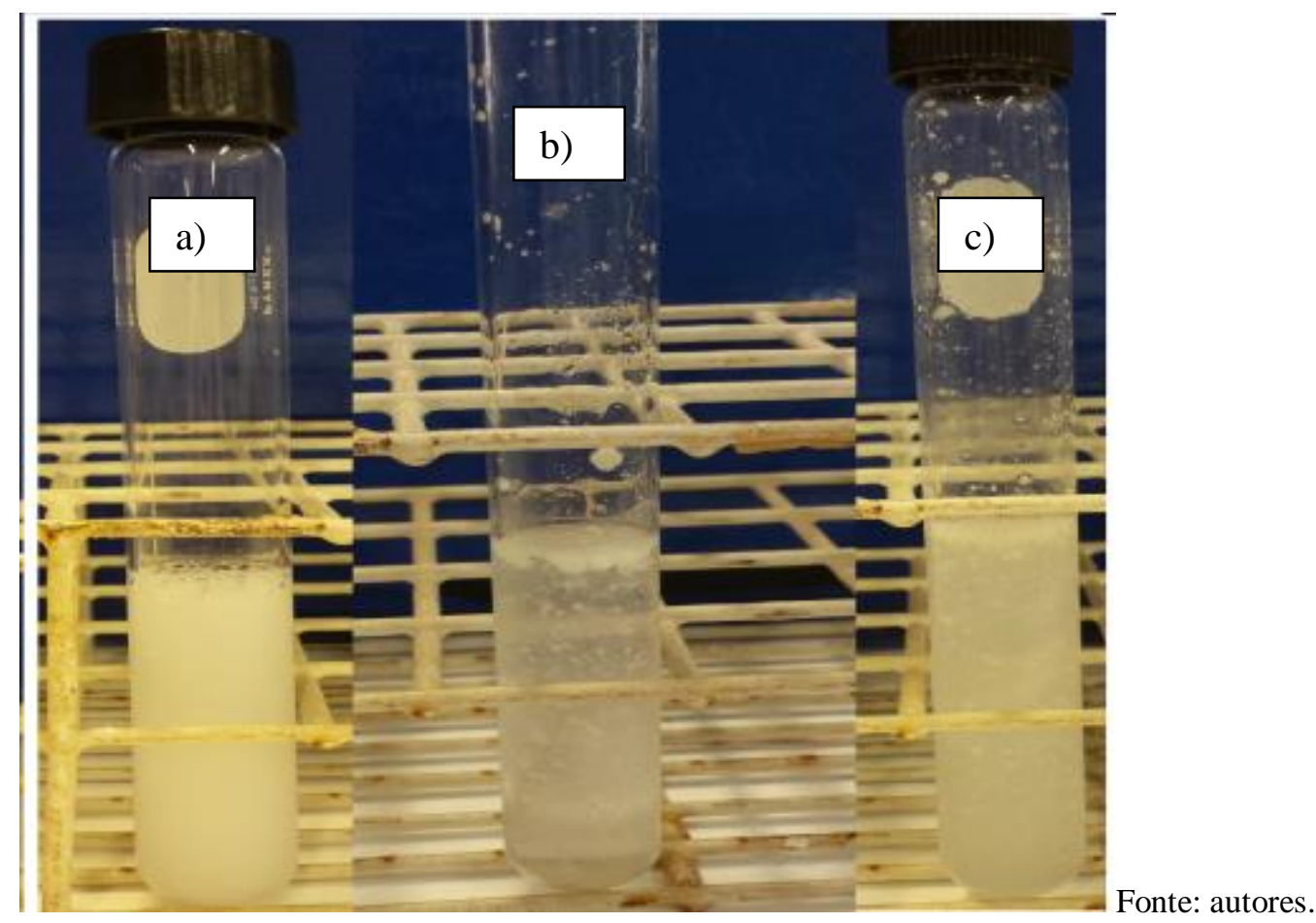

\section{RESULTADOS E DISCUSSÕES}

Os resultados são apresentados na Tabela 2. Sendo A1, A2 e A3: frações de azeite, B1, B2 e B3: frações de óleo de uva e C1, C2 e C3: frações de óleo de algodão, para os volumes de $125 \mu \mathrm{L}, 250 \mu \mathrm{L}$ e $350 \mu \mathrm{L}$, respectivamente. Todos os experimentos foram realizados em triplicata $(n=3)$. 
Tabela 2 - Resultados de análise das NE preparadas a partir de diferentes óleos: $\mathrm{A}=$ azeite; B = óleo de uva e C = óleo de algodão*

\begin{tabular}{cccc}
\hline Frações de óleo & $\begin{array}{c}\text { Diâmetro médio das } \\
\text { partículas }(\mathrm{nm})\end{array}$ & PdI & $\begin{array}{c}\text { Potencial Zeta }-(\zeta) \\
(\mathrm{mV})\end{array}$ \\
\hline A1 & $184,2 \pm 3,8$ & 0,449 & $-2,09 \pm 0,54$ \\
A2 & $168,9 \pm 6,5$ & 0,538 & $-15,0 \pm 0,25$ \\
A3 & $240,6 \pm 9,2$ & 0,252 & $-7,56 \pm 0,65$ \\
B1 & $488,2 \pm 12,9$ & 0,774 & $-5,13 \pm 4,70$ \\
B2 & $150,2 \pm 5,1$ & 0,040 & $-1,91 \pm 0,40$ \\
B3 & $187,9 \pm 3,5$ & 0,383 & $-4,30 \pm 0,60$ \\
C1 & $189,2 \pm 4,2$ & 0,338 & $-2,81 \pm 1,40$ \\
C2 & $109,2 \pm 2,5$ & 0,933 & $-5,44 \pm 0,80$ \\
C3 & $215,8 \pm 3,8$ & 0,917 & $-2,19 \pm 0,50$ \\
\hline
\end{tabular}

$* 1=$ volume de $125 \mu \mathrm{L} ; 2=$ volume de $250 \mu \mathrm{L}$ e $3=$ volume de $350 \mu \mathrm{L}$.

A partir da análise dos dados, é possível perceber a influência do volume de óleo nas propriedades físico-químicas das formulações. A utilização do óleo do tipo azeite (A1, A2 e A3) apresentou bons resultados nos três experimentos realizados, sendo que o menor diâmetro médio das partículas foi obtido para a formulação preparada com volume de $250 \mu \mathrm{L}$ (A2). O tamanho médio das partículas preparadas com o óleo de uva (B2 e B3) apresentou pouca variação, entre os volumes de 250 e $350 \mu \mathrm{L}$ (B2 e B3), porém, para o volume de $125 \mu \mathrm{L}$ (B1), as partículas apresentaram diâmetro maior que o esperado para esses sistemas coloidais. O PdI seguiu o mesmo padrão que o diâmetro, obtendo-se melhores resultados nos volumes maiores, B2 e B3 $(250$ e $350 \mu \mathrm{L})$. O óleo de algodão $(\mathrm{C} 1)$, por outro lado, demonstrou-se mais eficiente para o processo e nanoemulsificação em quantidades menores de óleo $(125 \mu \mathrm{L})$, em que apresentou PdI < 0,35, em comparação com os outros lotes, quando o PdI foi $>0,9$.

\section{CONCLUSÕES}

A partir destes resultados, é possível concluir que os óleos de azeite e uva, nas diferentes frações de volumes estudadas (A e C), apresentaram melhores propriedades físico-químicas às nanoemulsões, com tamanhos médios de partículas numa faixa de distribuição reduzida $(<250 \mathrm{~nm})$. Entretanto, os valores para o PdI indicam que as amostras de NE preparadas com azeite (A) apresentaram maior polidispersidade em suspensão, frente aos resultados obtidos para as amostras de NE preparadas com óleo de algodão (C). As etapas futuras deste trabalho de pesquisa, terão como objetivo o encapsulamento de corantes de origem biotecnológica nas NE aprovadas com maior estabilidade físico-química. 


\section{REFERÊNCIAS}

ANTON, N.; VANDAMME, T. F. Nano-emulsions and micro-emulsions: clarifications of the critical differences. Pharmaceutical research, v. 28, n. 5, p. 978-985, 2011.

PRIMO, F. L. Faculdade de Filosofia, Ciências e Letras de Ribeirão Preto Departamento de Química. 2006. Dissertação de Mestrado. Universidade de São Paulo. 